\title{
The "Crossfire Approach": Attracting Political Science Majors in Large-Lecture Sections of Introductory Courses
}

Jody C Baumgartner, East Carolina University

Jonathan S. Morris, East Carolina University

ABSTRACT In this article, we chronicle our experience in team-teaching large-lecture sections of "Introduction to American Government." A dual-instructor approach allows us to accommodate 250 students, which obviates the need for five separate sections (and instructors) of the course. In addition, our "Crossfire Approach," in which we engage one another in frequent and unstructured political debate, generates student interest in the course and in the political science major. Students who were enrolled in this course from 2007 through 2011 were significantly more likely to declare political science as their major than those who took it from any other instructor or either of us teaching it individually. This approach conserves departmental resources while simultaneously growing the program-a clear win-win situation.

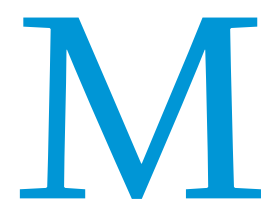

ost introductory political science courses are filled with students in their first year of higher education. Typically, as many as $80 \%$ have not yet declared a major (Ronan 2005) and they take the course to meet a social science and/ or general education requirement. However, because political science introductory courses typically have the largest enrollment, they arguably are the best way to reach potential majors. How can we effectively reach, engage, and ultimately interest students in these classes so that they might consider political science as their major course of study?

In this article, we chronicle our experience in team-teaching large-lecture sections of "Introduction to American Government" in the Fall semester. The two-instructor approach allows us to accommodate 250 students, replacing the five instructors who typically would be needed for 40 to 50 students in standard sections of the course. Doing so conserves scarce departmental resources.

The original mandate, however, included using this class to attract more political science majors. To this end, we developed an approach that we refer to as the "Crossfire Approach," wherein we engage in frequent and unstructured political debate with one another. Throughout the semester, we engage in what amounts to informed partisan bickering, similar to what happens on CNN's

Jody C Baumgartner is a professor in the department of political science at East Carolina University. He can be reached at jodyb@jodyb.net.

Jonathan S. Morris is an associate professor in the department of political science at

East Carolina University. He can be reached at morrisj@ecu.edu.
"Crossfire" and other "debate" programs. This approach highlights the themes of conflict and compromise in the American democratic process. Importantly, it also appears to generate more interest in political science among students.

Using data that tracked every student who enrolled in "Introduction to American Government" in our department from Fall 2007 to Spring 2011 ( $N=3,700)$, we show that those who were in our team-taught class were significantly more likely to declare political science as their major than those who took the course with any of the other 14 instructors teaching the same course during this period, including either of us teaching it individually.

The size of an academic program is an important consideration in the institutional resource-allocation process. All other factors being equal, larger programs warrant and attract more resources. The realities of higher education in a state-funded university all but demand that instructors and departments do more by expending the least amount of resources possible. The dual-instructor model for large classes is one way to stretch scarce resources. Furthermore, our approach has been shown empirically to generate greater student interest in the subject. Thus, our findings also have intrinsic pedagogical value. In summary, our findings suggest that the dual-instructor "Crossfire Approach" increases interest in the discipline using fewer resources.

\section{LARGE CLASSROOMS, TEAM TEACHING, AND CONFLICT IN THE CLASSROOM}

There is little doubt that large-lecture sections will be part of the higher-education landscape for the foreseeable future (Mulryan-Kyne 2010). This is despite concerns that large 
classrooms create an environment that may lead to a culture of disengagement for students and faculty (Cuseo 2007; McConnell and Sosin 1984; McKeachie 1980; Spahn 1999; Wulff, Nyquist, and Abbott 1987) and result in decreased student motivation and attentiveness (McConnell and Sosin 1984). The main problem seems to be that large-lecture sections often lack incentives for classroom engagement (Feigenbaum and Friend 1992) and that many students are seeking this passive environment when they take these courses.

Solutions to this problem have been proposed in various literatures. For example, Buskist and Wylie (1998) suggested administering a brief survey to students in large-section introductory psychology classes and discussing the findings to help students better understand themselves and their classmates. Diggs-Thompson (1999) discussed assigning focused small-group projects throughout the semester in large-section anthropology classes. A recent review of the literature identified various "active-learning" activities and approaches that might engage students in large-section classes, including "brainstorming, short writing activities followed by class discussion, quick surveys, think-pair-share, formative quizzes, debate, role playing and student presentations" (Mulryan-Kyne 2010; see also Bonwell and Eison 1991). One proposed idea was the introduction of drama into the classroom.

Based on this latter idea, we believe that the addition of partisan debate between two instructors in the classroom would engage and interest students. From the beginning, our assumption was that the spectacle of two university instructors arguing with one another in a classroom environment would be certain to attract students' attention. We are not aware of any literature that speaks directly to this proposition, but research supports the idea that introducing the unexpected or unorthodox into teaching can enhance engagement (Stander 1968; the same is apparently true in advertising-see Wells, Moriarty, and Burnett 1999). In this respect, the debate element in our class functions in a manner similar to humor, which typically revolves around the introduction of the unexpected and has been shown to have a positive effect on attention (Eisend 2009; Gelb and Zinkhan 1986).

\section{THE "CROSSFIRE APPROACH"}

Our department chair proposed the idea of a team-taught (i.e., dual-instructor) large-lecture section of our introductory course primarily to increase enrollment. We were asked to teach a large-lecture section (originally, 120 students; recently, 250) to eliminate the need for several individual sections. Since 2007 , this has been done every fall semester and, in one year, the spring semester as well. However, because an additional challenge was to create a more dynamic classroom environment, our thought was to introduce political debate between the two instructors.

The core of our team-teaching arrangement is that both instructors are present for every class period. In each session, one instructor leads the lecture and is responsible for presenting approximately two-thirds of the material. The second instructor fills in gaps, emphasizes important points, provides other examples, and occasionally brings up a related point. In this sense, the presentation is a joint exercise in which the secondary instructor is responsible for clarifying and enhancing material presented by the primary instructor. This alone breaks up the monotony that can develop in a standard single-instructor lecture-and likely results in a higher-quality presentation of the material.
The "debate" element comes into play several times during each class session. During the first class meeting, one instructor identifies as a liberal Democrat and the other as a conservative Republican. This sets up the potential for political disagreement between us. For example, as one instructor is making a point about the day's topic, the other might interject to add depth or insight and, in the process, introduce a clearly ideologically political point. ${ }^{1}$ The other instructor then interrupts or follows, starting an animated discussion. These debates are purposefully brief, rarely lasting more than a couple of minutes. Often-but not always-we conclude by finding common ground. At that point, we resume our presentation of the material.

An example exchange might proceed as follows:

Professor A: The point is that polarization, depending on how we define the term, may be on the increase among citizens and has clearly increased in Congress. This is especially true in the House of Representatives.

Professor B: Absolutely. In fact, we don't have to look any further than House Republicans for proof.

Professor A: Huh? Just Republicans?

Professor B: Sure! They're the ones doing wacky things like obstructing implementation of Obamacare.

Professor A: How is that an example of polarization? Don't you-by definition -need two sides to call it polarization?

Professor B: Obama was reelected in 2012. The Affordable Care Act was passed by both houses of Congress and signed by the president. The Supreme Court declared the law constitutional. Obamacare is the law of the land! House Republicans have no right to try and stop its implementation!

Professor A: Now, wait a minute-you know as well as I do that passing a law is not the same as implementation. The House is responsible for budgetary matters.

Professor B: Which means they're responsible for funding the law of the land!

Professor A: Or not funding, as they-as duly-elected representativessee fit. But you're right: Obama is the greatest president who ever

lived, and the new health care reform act won't bankrupt the country. Should we move on?

This example, although hypothetical, is entirely representative of the "crossfire" element of the class.

It is important to emphasize several points about the nature of the debate. First, and strictly speaking, the discussion is not political debate as much as it is partisan disagreement, much like what happens on programs such as CNN's "Crossfire." In other words, unlike actual formal debate, there is much interrupting and ad hominem attacks on one another (as well as politicians), questionable logic, and so on.

Second, the "debates" are not used to clarify points or to enhance the lecture material. We are not using the substance of the debate to teach about the day's topic. Rather, the purpose is to (1) capture students' attention; (2) illuminate, through demonstration, the themes of conflict and compromise in American politics; and (3) expose students to (at least) two sides of various issues. The debates are not designed to clarify the material.

Third, we do not disagree with the discipline's current understanding of a given topic; a nuanced discussion of the state of 
current research would only muddle the presentation in an introductory-level course.

Fourth, we clearly and emphatically distinguish between the analytical and the ideological. In other words, we work to ensure that students do not interpret our partisan points as fact.

Fifth, most issues in American politics are more complex than a simple left-right division might suggest. However, this is an introductory course and, with certain exceptions (e.g., immigration), we present issues as two-sided while noting that most are more nuanced than our presentation allows. In these cases, we encourage students to consider the more specialized upper-level political science courses. Moreover, our discussion is rarely a simple twosided argument: we sometimes agree with parts of one another's argument and/or note that particular issues (e.g., immigration) are complicated and cannot be reduced to two viewpoints.
We spent way too much time in class talking about things that weren't on the exam. They were so busy trying to make class fun that they didn't cover things that should have been covered. I don't want to go to class to cut up and have a good time. Make your point, cover what will be on the exam and that's all. If something is important enough to be discussed in class, it should be on the exam, [and] if it's not going to be on the exam, I don't want to hear about it.

Clearly, the partisan-debate approach to teaching American government is not for everyone. Nevertheless, the number of negative comments may not be a reliable gauge of how many students dislike our approach, inasmuch as the response rate for end-of-year surveys of students' perception of teaching typically is $25 \%$. However, it is possible that as many as one-quarter of the students dislike our approach. As the previous comment makes

\section{We are not using the substance of the debate to teach about the day's topic. Rather, the purpose is to (1) capture students' attention; (2) illuminate, through demonstration, the themes of conflict and compromise in American politics; and (3) expose students to (at least) two sides of various issues.}

The strength of the approach is our public (i.e., open) conflict over normative values associated with contemporary political issues, events, and leaders. Our disagreements often take us slightly afield from the topic of the day. Although it might be helpful to plan or script these exchanges to better relate them to the topic at hand, the personal chemistry between us works well when disagreement emerges spontaneously. At times, we can relate the disagreement to the specific topic. At other times, this is not possible and we cannot arrive at a consensus position. However, one of our objectives is to expose students to the reality of American political discourse, and we are quick to point out that our positions are representative in this regard. Therefore, even if the "debate" does not relate closely to the topic at hand, it has intrinsic value. By agreeing to disagree, we also demonstrate that conflict need not be confrontational. We often make this point, and it is evident to students that despite our differences, we enjoy one another's company.

\section{ANALYSIS}

Does this team-taught, conflict-centric approach engage students and make them more likely to want to continue their studies in political science? To examine this question, we present comments written in student evaluations administered anonymously at the end of each semester from 2008-2011. After eliminating those that did not directly address the debate aspect of the course, there were 101 comments: 75 positive and 26 negative.

The negative comments can be characterized as general discontent about the fact that our debating was either overdone or detracted from a more traditional presentation of the material. One student wrote, "I did not like that the two instructors argued politics in class so much. Although sometimes it's entertaining, I do not learn from it and I feel it is a waste of time." Several suggested that we "focus more on topics that are going to be tested in class lectures." The following quote of another student summarizes the tone and substance of the negative comments: clear, there are those who come to class with strict expectations regarding the presentation of material, and it is not likely that we can satisfy those students.

Also, it would be difficult to orient debate around some of the subjects we address, and some students expressed concern about that. Directly linking class debates to daily topics would be challenging. There is, for example, minimal interesting partisan debate that can be engaged in when discussing the congressional committee system or the federal nature of the judiciary. Moreover, doing so would risk confusing the analytical with the ideological, which must be avoided at this course level.

However, the positive survey comments outweighed the negative three to one. Most students referenced either one or both of two perceived advantages to the class structure. First, many liked the fact that both sides of various issues were represented. One student noted that "two professors with different views helps get both sides of the subject." Moreover, offering "both sides of any argument," claimed another, "is very effective in the learning process."

The second advantage emphasized in the positive comments was the excitement generated by debate between the instructors. Students agreed that there is a "great dynamic to the class especially because one professor is an open Democrat and the other professor is an open Republican." Other positive comments included the following:

- "Their opposing views grasp the majority of the class's interest!"

- "I love the way you guys teach the class-it was never boring!"

- "Never a dull moment."

- "Giving different points of view gives this course excitement."

In short, most students agreed that "the teaching method was exceptional." One frankly admitted, "[W] onderful class-wasn't thrilled about taking [this class] but this duo made it worthwhile!"

Perhaps the most promising comment focused on the course as it relates to the substantive reality of politics, especially in an 
age of polarized politics, cynicism, and apathy. One student wrote, "I like that [Instructor A] openly disagrees with [Instructor B] and offers his differing opinion. I love that both teachers have such opposite beliefs but are still able to work very well together; this shows students that it isn't impossible to get along with a person that has opposing views."

To summarize, positive comments emphasized the fact that the partisan debate between the two instructors exposed students to and helped them understand differences in opinion regarding a number of political issues and, in the process, made the course more exciting and interesting. In addition, our debates were tangible evidence of how differences and partisanship need not translate into an inability to work together.
To investigate further, we conducted a logistic regression in which the dependent variable was the major that each "Introduction to American Government" student ultimately declared. Political science majors were coded as " 1 " and all others as "o." We also controlled for our individually taught classes from Fall 2007 (i.e., our first year of team teaching) through 2011. These variables are labeled "Professor A" and "Professor B" in the model. The excluded category in the model includes all other sections of "Introduction to American Government." Because we have a nominal dependent variable, we conducted a logistic regression. The findings are presented in table 2.

The first model presented in table 2 (column two) shows that students who were enrolled in our team-taught class were significantly

\section{To summarize, positive comments emphasized the fact that the partisan debate between the two instructors exposed students to and helped them understand differences in opinion regarding a number of political issues and, in the process, made the course more exciting and interesting.}

In addition to this qualitative evidence, quantitative data show how effective this approach is in engaging students. We tracked every student who enrolled in the introductory course from Fall 2007 through $2011(\mathrm{~N}=3,700)$. The most popular majors at our large, public, southeastern university are professionally oriented, particularly education and business. Political science is a small- to moderately sized program.

Therefore, our sample was not randomly selected. However, the American government course qualifies for "foundations" (i.e., core) curriculum credit so it attracts students from a wide variety of majors and intended majors. Many of the students enrolled in the fall section are incoming freshmen who are assigned to the course by their academic adviser. It is therefore reasonable to expect that during the span of five years, our sample (i.e., population) was fairly representative of the entire student body. In terms of the political environment, the study encompasses the last two years of George W. Bush's tenure and Barack Obama's first three years. This provides confidence that the political environment did not affect our findings.

Table 1 outlines the percentage of students in "Introduction to American Government" courses who declared political science as their major, categorized by instructor. We compare all other American government instructors to the team-taught class, as well as those taught individually by us (labeled Instructor A and Instructor B). The table also categorizes these data by year. The findings show that significantly more students in our team-taught class eventually declared political science as their major than those in classes taught by other instructors. In total, $15.6 \%$ of students who were enrolled in the team-taught sections eventually declared political science as their major. This percentage easily exceeds the political science declaration rate of students who were enrolled in sections taught by other instructors $(6.2 \%)$ or individually by Instructor A or Instructor B (7.8\% and 3.6\%, respectively). The raw-number totals listed in the last column of the table demonstrate that the team-taught classes generated $50 \%$ of the 328 political science majors, even though only $28 \%$ of all "Introduction to American Government" students took the team-taught section. more likely to declare political science as their major when compared to all other instructors $(\mathrm{p}<0.001)$. To ensure that this effect was not simply from one of the team-teaching instructors, we controlled for the courses that each of us taught individually in the second model of table 2 (column three). Both individual effects are statistically insignificant, but the effect of the teamtaught class remains. In substantive terms, our findings equate to an additional 9.3 majors per 100 students, which in a class of 200 to 250 is 18 to 23 students more than what would be generated by a traditional "Introduction to American Government" course.

\section{WHY IT WORKS}

This dual-instructor approach generates interest and attracts more political science majors for three interrelated reasons. First, each of

Table 1

Percentage of "Introduction to American Government" Enrollees Who Declared Political Science as a Major, by Section (Fall 2007-Fall 2011)

\begin{tabular}{lcccccc} 
Instructor & $\mathbf{2 0 0 7}$ & $\mathbf{2 0 0 8}$ & $\mathbf{2 0 0 9}$ & $\mathbf{2 0 1 0}$ & $\mathbf{2 0 1 1}$ & Total \\
\hline All other instructors & $\mathbf{8 . 1 \%}$ & $6.2 \%$ & $\mathbf{7 . 3 \%}$ & $5.6 \%$ & $4.6 \%$ & $6.2 \%$ \\
\cline { 2 - 7 } & $(31)$ & $(31)$ & $(39)$ & $(34)$ & $(28)$ & $(163)$ \\
\hline Instructor A & - & - & $9.4 \%$ & $4.6 \%$ & - & $7.8 \%$ \\
\cline { 2 - 7 } & & & $(8)$ & $(2)$ & & $(10)$ \\
\hline Instructor B & - & - & $2.2 \%$ & - & $5.3 \%$ & $3.6 \%$ \\
\hline Instructors A and B & $19.0 \%$ & $15.8 \%$ & $13.6 \%$ & $19.1 \%$ & $12.8 \%$ & $15.6 \%$ \\
\cline { 2 - 7 } & $(22)$ & $(47)$ & $(32)$ & $(34)$ & $(30)$ & $(165)$ \\
\hline All sections & $10.6 \%$ & $9.8 \%$ & $9.2 \%$ & $8.6 \%$ & $6.8 \%$ & $8.9 \%$ \\
\cline { 2 - 7 } & $(53)$ & $(78)$ & $(71)$ & $(68)$ & $(58)$ & $(328)$ \\
\hline & *Raw numbers are in parentheses. & & & & &
\end{tabular}


Table 2

Political Science Major by Instructor

\begin{tabular}{lcc} 
Instructor & \multicolumn{2}{c}{$\begin{array}{c}\text { Student Declared Political Science as } \\
\text { his/her Major? (1=yes; } 0 \text { =no) }\end{array}$} \\
\hline Model 1 & Model 2 \\
\hline Ieam-taught course & $1.03(.12)^{*}$ & $1.03(.12)^{*}$ \\
\hline Instructor A only & - & $.24(.23)$ \\
\hline Constructor B only & - & $-.56(.59)$ \\
\hline Log Likelihood & $-2.72(.08)^{*}$ & $-2.72(.08)^{*}$ \\
\hline N & -1070.23 & -1069.43 \\
\hline
\end{tabular}

Note: Cell entries are logit coefficients with standard errors in parentheses. $*=0.001$.

us represents a different side of the political spectrum. Although it may be the case that Instructor A is somewhat more liberal than Instructor B is conservative, this is irrelevant. Each side is represented; therefore, students can hear both viewpoints on a variety of different issues.

Second, each of us, in a relatively civil manner, is willing to act our partisan character in class. We are aware of research that has found a link between exposure to televised partisan incivility and viewer discomfort and cynicism toward politics (Forgette and Morris 2006; Mutz and Reeves 2005). However, other research shows that competing presentations of information in support of a political opinion complemented with factual evidence can stimulate interest and engagement in politics (Franz et al. 2008; Geer 2008). Thus, we are careful to end most in-class arguments with an agreement to disagree.

Third, there is a great deal of personal chemistry between the two instructors, which is evident in our presentation. We have collaborated on several research projects in the past decade, presented papers together at conferences, and worked on a variety of service-oriented projects-and we are good friends.

It can be argued that our findings are limited by the fact that alternative explanations for students declaring political science as their major have been ignored. This is a limitation of our data, which are not survey data but rather simple records obtained from the registrar regarding which students took the course, from whom, and which major they ultimately declared. As previously noted, our assumption is that there is little systematic bias in our population as the result of how students and advisers select the course, but we cannot be entirely certain that this is the case.

One lesson learned from this exercise is that we might take more care in selecting debate issues. In particular, greater attention could be given to link the debates to the regularly scheduled topic of the day. Anecdotal comments from students suggest that this may clarify questions related to text topics and exams.

Of course, this "Crossfire Approach" to teaching introductory courses in American government and politics may not be a solution for all departments. For example, the debate dynamic may be too overpowering in a small classroom setting, and it may be difficult to justify assigning more than one instructor to a small section. This latter scenario could be addressed by having course instructors invite one or more colleagues to the class as informal guests a few times each semester. These class sessions could be presented to students as special situations in which outside expertise is desirable. Then, during the class period, a partisan "argument" between the two instructors might just "happen to break out."

Research suggests that educators in large classroom settings pursue innovative methods to increase student interest (Huerta 2007; Snell and Steinert 1999). This approach has allowed us to teach a high volume of new students while also generating more interest in the major than more traditional approaches.

\section{NOTE}

1. Neither instructor makes ideologically charged political points in class when individually teaching this course.

\section{REFERENCES}

Bonwell, Charles C., and James A. Eison. 1991. "Active Learning: Creating Excitement in the Classroom." ASHE-ERIC Higher Education Report No. 1. Washington, DC: George Washington University, School of Education and Human Development.

Buskist, William, and Devin Wylie. 1998. "A Method for Enhancing Student Interest in Large Introductory Classes.” Teaching of Psychology 25 (2): 203-205.

Cuseo, Joe. 2007. “The Empirical Case against Large Class Size: Adverse Effects on the Teaching, Learning, and Retention of First-Year Students." Journal of Faculty Development 2 (1): 5-21.

Diggs-Thompson, Marilynne. 1999. "Building Student Interest in Large Classes." Anthropology News 40 (4): 23-4.

Eisend, Martin. 2009. "A Meta-Analysis of Humor in Advertising." Journal of the Academy of Marketing Science 37 (2): 191-203.

Feigenbaum, Elyssa., and Ronald Friend. 1992. "A Comparison of Freshmen and Upper Division Students' Preferences for Small and Large Psychology Classes." Teaching of Psychology 19 (1): 12-16.

Forgette, Richard, and Jonathan S. Morris. 2006. "High-Conflict Television News and Public Opinion." Political Research Quarterly 59 (3): 447-56.

Franz, Michael M., Paul B. Freedman, Kenneth M. Goldstein, and Travis N. Ridout 2008. Campaign Advertising and American Democracy. Philadelphia: Temple University Press.

Geer, John G. 2008. In Defense of Negativity: Attack Ads in Presidential Campaigns. Chicago: University of Chicago Press.

Gelb, Betsy D., and George M. Zinkhan. 1986. "Humor and Advertising Effectiveness after Repeated Exposures to a Radio Commercial." Journal of Advertising 15 (2): 15-20, 34 .

Huerta, Juan Carlos. 2007. “Getting Active in the Large Lecture.” Journal of Political Science Education 3 (3): 237-49.

McConnell, Campbell R., and Kim Sosin. 1984. "Some Determinants of Student Attitudes toward Large Classes." Journal of Economic Education 15 (3): 181-90.

McKeachie, Wilbert J. 1980. "Class Size, Large Classes, and Multiple Sections." Academe 66 (1): 24-7.

Mulryan-Kyne, Catherine. 2010. "Teaching Large Classes at College and University Level: Challenges and Opportunities." Teaching in Higher Education 15 (2): 175-85.

Mutz, Diana C., and Byron Reeves. 2005. "The New Videomalaise: Effects of Televised Incivility on Political Trust." American Political Science Review 99 (1): 1-15.

Ronan, Gayle B. 2005. "College Freshman Face Major Dilemma." Available at www. nbcnews.com/id/10154383/\#.UqdUriembSg. Accessed Jan. 13, 2013.

Snell, Yvonne, and Linda S. Steinert. 1999. "Interactive Lecturing: Strategies for Increasing Participation in Large Group Presentations." Medical Teacher 21 (1): 37-42.

Spahn, Karen. 1999. “Class Size and Faculty Effectiveness and Quality.” Paper presented at the 39th Annual Institutional Research Forum, Seattle, WA.

Stander, Philip. 1968. "The Vital Role of the Unorthodox in College Teaching." Journal of Teacher Education 19 (2): 133-8.

Wells, William D., Sandra Moriarty, and John Burnett. 1999. Advertising: Principles and Practice. 7 th ed. New York: Prentice Hall.

Wulff, Donald H., Jody D. Nyquist, and Robert D. Abbott. 1987. "Students' Perceptions of Large Classes." New Directions for Teaching and Learning 32 (winter): 17-30. 